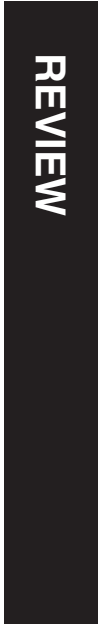

\section{How strong is the relationship between glaucoma, the retinal nerve fibre layer, and neurodegenerative diseases such as Alzheimer's disease and multiple sclerosis?}

\begin{abstract}
Glaucoma is a neurodegenerative disorder with established relationships with ocular structures such as the retinal nerve fibre layer (RNFL) and the ganglion cell layer (GCL). Ocular imaging techniques such as optical coherence tomography (OCT) allow for quantitative measurement of these structures. OCT has been used in the monitoring of glaucoma, as well as investigating other neurodegenerative conditions such as Alzheimer's disease (AD) and multiple sclerosis (MS). In this review, we highlight the association between these disorders and ocular structures (RNFL and GCL), examining their usefulness as biomarkers of neurodegeneration. The average RNFL thickness loss in patients with AD is $11 \mu \mathrm{m}$, and $7 \mu \mathrm{m}$ in MS patients. Most of the studies investigating these changes are cross-sectional. Further longitudinal studies are required to assess sensitivity and specificity of these potential ocular biomarkers to neurodegenerative disease progression.

Eye (2015) 29, 1270-1284; doi:10.1038/eye.2015.158;

published online 4 September 2015
\end{abstract}

College London,

St Thomas' Hospital Campus, 3rd Floor South Wing Block D, Westminster Bridge Road, London SE1 7EH, UK

Tel: +44 (0)20 7188 9055; Fax: +44 (0)20 71886718 . E-mail: chris.hammond@ kcl.ac.uk

Received: 22 May 2015 Accepted in revised form: 27 July 2015

Published online:

4 September 2015
E Jones-Odeh ${ }^{1}$ and CJ Hammond ${ }^{1,2}$

and monitoring of the structural changes associated with glaucoma. However, objective detection of defects in the peripapillary retinal nerve fibre layer (RNFL) by ophthalmoscopy is difficult. The relationship between glaucoma progression and the structural changes observed at the ONH, RGC layer, and RNFL in glaucoma is well established. ${ }^{1-4}$

Early diagnosis and treatment of glaucoma is vital to maintain visual field, as loss of RGCs is irreversible, ${ }^{5}$ and even before any detectable visual field defects, there is a substantial loss of RGCs. Morphological abnormalities can develop 3-5 years before any functional loss is detected. ${ }^{6}$

Since the introduction of ocular imaging techniques such as optical coherence tomography (OCT), peripapillary RNFL thickness measurements have been used for the detection and monitoring of glaucoma. ${ }^{7,8}$ However, the use of OCT has extended beyond RNFL

measurements for glaucoma, and has also been used in the investigation of other

neurodegenerative disorders such as Alzheimer's disease (AD) ${ }^{9-11}$ and multiple sclerosis (MS). ${ }^{12-14}$ In addition, given the similarities of brain and retinal foetal angiogenesis, ${ }^{15,16}$ retinal microvasculature has also been investigated as a biomarker of changes in cerebral vasculature and cognitive decline. ${ }^{17-19}$

In this review, we examine the relationships between glaucoma, neurodegenerative disease, and cognitive impairment, and the use of RNFL thickness and RGC loss as potential ocular biomarkers for neurodegenerative disorders such as AD and MS. We review the strength of associations between RNFL and RGC and 
neurodegeneration, and whether they are sufficient to be used in a diagnostic and prognostic capacity.

\section{Glaucoma and the RNFL}

As RGCs are lost in glaucoma, there is atrophy of the retinal nerve fibres, causing the RNFL to decrease in thickness. ${ }^{1-4}$ Before OCT and other imaging techniques, ${ }^{20}$ in order to monitor RNFL changes, clinicians depended on ophthalmoscopy, red-free fundus photographs ${ }^{21}$ in vivo, or histological examination of the RNFL and ONH from enucleated eyes or post-mortem. ${ }^{2}$

Quigley and Sommer ${ }^{22}$ gave a detailed description on 'how to use the nerve fibre layer examination in the management of glaucoma'. The RNFL develops from RGC axons converging on the disc to form bundles seen as bright white lines as they reflect light back toward the examiner's eye. The thickness of the RNFL bundles is greater at the disc and becomes less so peripherally, leading to increased reflections around the $\mathrm{ONH}$.

Therefore, the thicker the RNFL bundles, the brighter the reflection, with the brightest reflections seen in the vertical meridian. Using green light for retinal illumination produces a dark background that allows for better visualisation of these bundles. They described an early sign of glaucomatous change in the RNFL: a 'wedge defect'. This occurs as a result of local RNFL atrophy contrasting with adjacent normal bright RNFL. ${ }^{22}$

Defects in the RNFL are difficult to quantify in vivo on clinical examination or photography. There are several technologies that have been used for measuring the RNFL in vivo. These include scanning laser polarimetry, confocal scanning laser ophthalmoscopy, and OCT.

\section{Scanning laser polarimetry}

This method was first used for in vivo measurements of RNFL thickness in patients with glaucoma in $1995 .^{23}$ Weinreb et al used a scanning laser polarimeter (the Nerve Fibre Analyzer, Laser Diagnostic Technologies, San Diego, CA, USA) to measure estimated RNFL thickness in normal patients and patients with glaucoma. This instrument utilises the optical properties of the parallel bundled birefringent retinal nerve fibres to measure the phase shift or retardation of reflected polarised light. These retardation measurements correspond to the amount of tissue through which the polarised light has passed, and therefore estimate RNFL thickness. A more recent device using this imaging technique is the GDx (Carl Zeiss Meditec, Vista, CA, USA), which, in various guises, was examined as a diagnostic and monitoring tool for glaucoma. ${ }^{24-28}$

\section{Confocal scanning laser ophthalmoscopy}

This imaging technique has mainly been used for retinal surface mapping and estimation of RNFL thickness from retardation of light that has passed through the birefringent RNFL. A laser scans the retina and obtains a two-dimensional map reflected from the retinal surface, while a detector measures the intensity of the reflected light to allow three-dimensional imaging of the $\mathrm{ONH}$ and peripapillary structures. A reference plane automatically placed along the contour line of the optic disc is then used to calculate RNFL thickness. An example of an instrument using this imaging modality is the Heidelberg retinal tomograph (Heidelberg Engineering, GmBH, Heidelberg, Germany), initially designed for disc imaging and for recognition of early glaucomatous structural changes. ${ }^{29,30}$

\section{Optical coherence tomography}

OCT is now the most commonly used optical imaging technique for the measurement of the RNFL, and seems likely to supersede the other technologies, given it is ubiquitous in eye departments, with a vital role in monitoring retinal disease. Since its development 24 years ago, OCT has allowed for non-invasive optical imaging and in vivo quantitative measurements of the ONH and RNFL. OCT uses low-coherence interferometry to calculate RNFL thickness by measuring the interval of light backscattered from the retina and a reference mirror. Many studies have used OCT measurements of the RNFL to investigate early signs and patterns of glaucomatous damage. 7,31,32

All methods consistently and quantitatively assess RNFL in glaucoma, a neurodegenerative disease. Given this scenario, there has been interest as to whether RNFL measurements may be used as proxy measures of global axonal loss in neurodegenerative diseases of the brain, and indeed whether the same pathological processes may be affecting RGCs as in brain cortex.

\section{Glaucoma, AD, and the RNFL}

$\mathrm{AD}$ is the most common form of age-related progressive dementia, affecting approximately over 26 million people worldwide. ${ }^{33}$ AD leads to irreversible cognitive decline, memory loss, and results in functional and behavioural problems, which interfere with a person's independence and ability to perform daily activities. This condition places a substantial financial strain on society, costing approximately 210 billion US dollars per year in the United States alone. ${ }^{34}$ Therefore, great effort has been expended to explore inexpensive, non-invasive diagnostic tests that can identify early signs of AD before any manifestation of the associated symptoms. Several biomarkers have already been investigated for detecting 
$\mathrm{AD}$ and its intermediate endophenotype of mild cognitive impairment (MCI), however, these methods are largely invasive and expensive. These methods include analyses of blood and CSF, neuroimaging, and genetic testing. ${ }^{35,36}$

\section{Pathophysiology of $A D$}

$\mathrm{AD}$ results in neuronal cell death in the brain as a result of accumulation of extracellular beta amyloid $(\mathrm{AB})$ protein and intracellular hyperphosphorylated tau protein and neurofibrillary tangles. The accumulation of the $\mathrm{AB}$ protein interferes with inter-neuronal communication via synapses, whereas the build-up of tau protein affects the transport of essential nutrients within the neurone itself. These processes are believed to contribute to neuronal cell death, which in turn leads to widespread cerebral atrophy and in turn cognitive and functional impairment. ${ }^{34}$

It has been suggested, however, that the deposition of amyloid protein is not solely responsible for the rate of cognitive decline in AD. Research has shown that neurodegeneration, depicted as atrophy on magnetic resonance imaging (MRI) occurs before cognitive decline and also reflects the rate of cognitive deterioration. ${ }^{37}$ It is believed that a combination of neurodegeneration and amyloid dysmetablolism is responsible for the major pathological changes associated with AD.

Significant permanent neuronal damage may be present up to 20 years before any signs of cognitive decline become apparent. ${ }^{36-38}$ Therefore, there is an urgent need for early detection of $\mathrm{AD}$ and screening methods that can identify cognitively normal individuals with structural changes and a greater risk of developing AD for early intervention.

Non-ocular biomarkers for AD that have been investigated include genetic markers such as mutations in the Presenilin genes 1 and 2, and the amyloid precursor gene, which have been linked to familial early onset $\mathrm{AD}$, and the apolipoprotein E gene, which has long been recognised as a major risk factor for the sporadic form of later onset $\mathrm{AD} .{ }^{35}$ Other biomarkers such as parietal grey matter atrophy, greater right hippocampal, and parahippocampal activation have been identified through MRI brain imaging. Patients carrying the Presenilin 1 gene have been reported to have significantly higher concentrations of plasma and CSF AB 1-42,36 although these findings have not always been replicated. ${ }^{39}$ These biomarkers, although informative, are invasive, time consuming, and expensive. A non-invasive ocular biomarker that has been investigated is the RNFL.

\section{Glaucoma and AD}

Given both glaucoma and AD are chronic, neurodegenerative, and age-related diseases, scientists have explored whether they share common pathophysiological mechanisms and therefore are associated. These mechanisms include neuroinflammation, ${ }^{40}$ high levels of tumour necrosis factor alpha, ${ }^{41,42}$ and upregulation of complement component 1q. ${ }^{43,44}$ In addition, $A B$ 1-42 and tau protein have been implicated in the pathogenesis of both AD and glaucoma. AB 1-42 levels have been shown to be significantly decreased and tau protein levels to be increased in the CSF of patients with AD when compared with controls. ${ }^{45}$ Yoneda et al $^{46}$ have reported similar findings obtained from vitreous fluid analysis of patients with glaucoma. There appears to be similar apoptotic processes in RGC death in patients with glaucoma and neuronal cell death in AD. ${ }^{47}$ Furthermore, histopathological studies conducted by Sadun and Bassi ${ }^{48}$ have provided evidence that the largest RGCs, the M cells, may be involved in the primary neurodegenerative process in the eyes of $\mathrm{AD}$ patients.

McKinnon et al ${ }^{49}$ have also suggested that RGC death in glaucoma mimics $\mathrm{AD}$ at a molecular level because of chronic neurotoxicity from $\mathrm{AB}$ deposition. Using an experimental glaucoma rat model with chronic ocular hypertension, the researchers demonstrated increased production of $A B$ in the RGCs in rats, which was attributed to abnormal amyloid precursor protein (APP) processing and activation of caspases 8 and 3 . The authors suggested that these abnormalities lead to a build-up of $\mathrm{APP}$, which in turn activates caspases and upregulation of AB production. This 'vicious cycle' of gradual AB buildup in RGCs leading to axonal loss and neuronal cell death, could possibly explain the progressive nature and association between AD and glaucoma.

Patients with AD may have a significantly higher risk of glaucoma and vice versa. ${ }^{50-52}$ Bayer et al ${ }^{53}$ attributed a five times greater risk of visual field defects and optic disc cupping in patients with AD to a higher prevalence of glaucoma. However, given no AD patients had ocular hypertension (in comparison with $7.5 \%$ of controls) and had no family history of glaucoma, it may be visual field abnormalities were not due to glaucoma and reflect difficulties in performing psychophysical visual field tests in AD patients. A subsequent study by the same authors ${ }^{54}$ showed an accelerated progression of visual field defects in patients with open-angle glaucoma and AD when compared with patients with open-angle glaucoma but without AD. However, given possible selection bias, a small sample size, non-blinded observers, and use of fundus photographs rather than more objective RNFL measures, these results need to be considered with caution. Visual field and optic nerve changes may not be specific to $\mathrm{AD}$ but have also been demonstrated in patients with Parkinson's disease. ${ }^{55}$ 
A recent systematic review by Tsilis et al ${ }^{56}$ identified eight pertinent studies exploring the relationship between glaucoma and AD (Table 1). The studies were conducted over a wide geographical area, often with small sample sizes: the largest study ${ }^{57}$ of 63325 participants showed an inverse association between AD and glaucoma. Metaanalysis suggested that patients with AD had a decreased risk of glaucoma compared with controls (RR, 0.92; 95\% CI, 0.89-0.94; $I^{2}, 89 \%$; $\left.P_{\text {heterogeneity, }}<0.001\right)$. Results were skewed by the largest study, but even when excluded, there was still high heterogeneity. The two largest studies $^{57,58}$ in this review showed a protective association between AD and glaucoma, whereas the smaller studies suggested greater risk. Methodology varied; half of the studies evaluated both diseases crosssectionally, 51,53,55,59,60 limiting ability to make conclusions about causality and progression. Smaller case-control studies tended to adjust for age and sex only, whereas the larger studies adjusted for other confounding variables. The largest study by $\mathrm{Ou}$ et $a{ }^{57}$ collected retrospective diagnostic codes from Medicare claims records to identify 63325 individuals with glaucoma and matched these participants with controls without glaucoma, AD, or dementia at recruitment. There may be misclassification bias as significant proportions of patients with glaucoma (and AD) in the population are undiagnosed.

These results suggest that the relationship between glaucoma and AD is complex, and many studies are flawed because of sample size, possible selection bias, and misattribution of visual field defects assessed by psychophysical testing to glaucoma. Therefore, it is important that well designed, longitudinal studies with adequate follow-up are conducted to establish the relationship between these two neurodegenerative processes.

Table 1 Summary table of the associations between glaucoma and $\mathrm{AD}$

\begin{tabular}{|c|c|c|}
\hline Study (reference) & $\begin{array}{l}\text { Number } \\
\text { of cases }\end{array}$ & $\begin{array}{c}\text { Relative risk } \\
(95 \% \text { confidence interval) }\end{array}$ \\
\hline \multicolumn{3}{|c|}{ Studies investigating risk of developing POAG in patients with $A D$} \\
\hline Tamura et al ${ }^{51}$ & 172 & $3.13(1.67-5.85)$ \\
\hline Bayer et al ${ }^{53}$ & 112 & $6.41(2.56-16.1)$ \\
\hline Bayer et $a l^{55}$ & 49 & $4.70(1.95-11.4)$ \\
\hline Chandra et al ${ }^{59}$ & 7195 & $2.60(1.06-6.43)$ \\
\hline \multicolumn{3}{|c|}{ Studies investigating risk of developing $A D$ in patients with $P O A G$} \\
\hline Ekstrom and Kilander ${ }^{126}$ & 174 & $1.09(0.69-1.74)$ \\
\hline Cumurcu et al $l^{60}$ & 21 & $5.44(1.88-15.6)$ \\
\hline Ou et al ${ }^{57}$ & 63325 & $0.91(0.88-0.93)$ \\
\hline Kessing et $a l^{58}$ & 11721 & $0.76(0.56-1.05)$ \\
\hline
\end{tabular}

Abbreviation: POAG, primary open-angle glaucoma. Results table adapted from Tsilis et al. ${ }^{56}$

\section{The eye in $\mathrm{AD}$}

Visual disturbance can be an early symptom in AD reflecting neuronal damage of cerebral visual pathways ${ }^{61}$ and insufficiency of acetylcholine, an essential neurotransmitter in the visual system. ${ }^{62,63}$

Histopathological evidence shows neuritic plaques and neurofibrillary tangles in visual cortex of patients with $\mathrm{AD}$, even occurring before hippocampal involvement in cognitively intact patients with preclinical AD. ${ }^{61}$ Visual problems may therefore precede memory impairment, particularly in the posterior cortical atrophy variant of AD. Visual deficits include abnormalities in visual field, colour vision, contrast sensitivity, motion perception, visuo-spatial construction, visual attention, visual memory, and fixation. ${ }^{64}$ However, none of these deficits are pathognomonic or diagnostic of AD.

It has been generally believed visual disturbance in $\mathrm{AD}$ is cortical in origin, rather than from pathology of the retina or optic nerve. ${ }^{65}$ The distinctive features found in the brains of patients with $\mathrm{AD}$ (ie, neuritic plaques and neurofibrillary tangles) had not been found in the human retina, ${ }^{66}$ until a recent study identifying amyloid plaques in the retinas of AD patients. ${ }^{67} \mathrm{AB}$ proteins, tau, and APPs have also been found in 'aged' human retinas. ${ }^{68}$

Furthermore, AB plaques, hyperphosphorylated tau, and retinal microvascular neuro-inflammation have been identified in the retinas of $\mathrm{AD}$ transgenic mice. ${ }^{69,70}$

The main ocular biomarker investigated for $\mathrm{AD}$ has been thinning of the RNFL, as this may reflect both generalised neurodegeneration and local involvement, and this is reviewed below. Other ocular biomarkers investigated in AD include pupillary abnormalities: hypersensitivity to pupillary dilatation with cholinergic antagonist eye drops, ${ }^{71-73}$ supersensitive pupillary response to cholinergic agonists, ${ }^{74}$ and altered pupil flash responses. ${ }^{75,76} \mathrm{AB}$ deposition (AB 1-40 and $\mathrm{AB} 1-42$ ) has been found in the lens with comparable concentrations to those in the brain. ${ }^{77} \mathrm{AB} 1-40$ has also been found in aqueous humour with comparable concentrations in the $\mathrm{CSF}^{77}$ and $\mathrm{AB} 1-42$ in the vitreous humour. ${ }^{46}$ Specific equatorial supranuclear cataracts have been found in patients with $\mathrm{AD}$ with colocalisation with $\mathrm{AB}$ deposits in the lens cytosolic proteins. ${ }^{77}$ Further research is required to determine the precise link between the presence of these proteins and cataracts to AD.

Retinal vasculature may also be a biomarker for AD. AD patients had significantly reduced venous blood column diameter and venous blood flow rate (measured by laser Doppler) compared with age-matched controls. ${ }^{78}$ Wong et l $^{19}$ also demonstrated changes in retinal microvasculature were independently associated with poorer cognitive function. Glaucoma, particularly normal tension glaucoma, has a vascular component, and there is 
evidence of microvascular abnormalities in AD and multiinfarct dementia; 79,80 the advent of improved vascular imaging with OCT angiography opens up the possibilities of future retinal biomarkers of the brain's microvascular structure.

\section{The RNFL in AD}

Histological studies have found a reduction in RNFL thickness in patients with AD in comparison with normal controls. ${ }^{66}$ Early studies with retinal photography showed a higher proportion of AD patients with RNFL abnormalities when compared with controls. ${ }^{52,81}$ However, photography is difficult in patients with advanced $\mathrm{AD}$, which led to inter-observer disagreement in almost a quarter of subjects in one study. ${ }^{81}$ Given technical difficulties, and a lack of quantitative analysis, retinal photography is limited as a biomarker for diagnosis and progression of AD.

Parisi et al, ${ }^{11}$ using OCT, showed thinning of the RNFL in all quadrants in AD patients compared with agematched normal control subjects. The thinning correlated with abnormal retinal function tested with pattern electroretinogram (PERG). ${ }^{11}$ Although statistical significance was achieved, the sample size was very small (17 subjects and 14 controls) limiting the generalisability of these results. Other relatively small OCT case-control studies have demonstrated similar findings. ${ }^{10,82}$ Paquet et $a l,{ }^{83}$ including subjects with $\mathrm{MCI}$ and mild AD, as well as moderate-to-severe $\mathrm{AD}$, showed that RNFL thickness in all groups of patients was significantly reduced, replicated by Kesler et al. ${ }^{84}$ These data suggest that the RNFL may be affected in early AD (ie, in MCI), and therefore may be a useful biomarker of probable development of cognitive impairment in the future. Studies have shown consistent RNFL loss, summarised in Table 2, and this loss seems to be particularly apparent in the superior, and inferior, quadrants of patients with cognitive impairment (Table 2).

The superior quadrant seems to be particularly affected in $\mathrm{AD}$ when compared with controls, reported by Berisha et $a l^{78}$ in a study of only nine patients, and Kesler et al ${ }^{84}$ in a study of $30 \mathrm{AD}$ patients. In addition, the latter study found inferior RNFL thickness to be significantly decreased in the AD group and also 24 subjects with $\mathrm{MCI}$ when compared with controls $(110.1 \pm 19.1$ and $111.9 \pm 16.1$ (mean \pm SD) $\mu \mathrm{m}$ versus $127.0 \pm 15.5 \mu \mathrm{m}$ ). The specificity of superior retinal neurodegeneration is supported by Trick et al ${ }^{85}$ who observed pronounced visual field loss in the inferior visual field of patients with AD. There was also a decreased global visual sensitivity in patients with severe dementia, which may suggest progressive loss of retinal sensitivity, in addition to the cerebral neurodegenerative processes.
Peripapillary RNFL loss in all four quadrants has been reported by other investigators using OCT. ${ }^{11,82}$ However, the subjects in these studies had more advanced AD when compared with those in the earlier studies. The range of MMSE scores in the Berisha et al group was 17-30, whereas those reported by Iseri et al ${ }^{82}$ were 8-28 and 11-19 in the study by Parisi et al. ${ }^{11}$ This further supports the notion that early retinal changes in AD may be confined to inferior and superior retina. Other studies have shown a significant correlation between RNFL thickness and MMSE scores in patients with MCI and $\mathrm{AD}^{86}$ and RNFL thickness has been significantly associated with other cognitive domains including reaction times. ${ }^{87}$ However, the findings are not universal: both an inverse association ${ }^{88}$ and no association ${ }^{89}$ between RNFL and cognitive test scores have been reported. A large-scale population-based study ${ }^{90}$ showed that better cognitive performance was significantly associated with a thicker RNFL $\left(r^{2}=0.028, P=0.03\right)$ in healthy young individuals without any cognitive impairment, but there were no significant associations found in older participants. This raises the question of ascertainment bias in clinic-based studies. However, a majority of the evidence demonstrates reduced RNFL thickness in patients with cognitive dysfunction.

\section{The ganglion cell layer in AD}

The ganglion cell complex is made up of the RNFL (the axons of the ganglion cells), the ganglion cell layer (GCL), which comprises the cell bodies, and the inner plexiform layer (the RGC dendrites). These are the three innermost layers of the retina. The macula contains a significant proportion of RGCs ${ }^{91}$ and therefore macular volume and thickness measurements via OCT can be useful ocular biomarkers. With advances in OCT development, segmentation of distinct layers of the retina is now possible, allowing for quantitative measurements of both neuronal (RGC) and axonal (RNFL) degeneration. Iseri et $a l^{82}$ found total macular thickness and volume of $\mathrm{AD}$ patients were significantly reduced and related to the degree of cognitive impairment. Morphologic deficits, such as a reduction in the number of RGCs and optic nerve axons, have been linked to AD and identified via histopathological studies. ${ }^{66}$ A study by Blanks et al ${ }^{92}$ demonstrated significant RGC degeneration in 14 of 16 AD patients. The degree of RGC pathology was consistent with the degree of ONH degeneration and marked RGC loss was associated with RNFL atrophy. The study found no neurofibrillary tangles, neuritic plaques or amyloid deposits in the retinas or optic nerves, suggesting that the loss of ganglion cells and their fibres was secondary to the neuronal degenerative processes in AD. Further work from the same group corroborated the findings, reporting 
Table 2 Summary table of relationship between RNFL thickness and AD

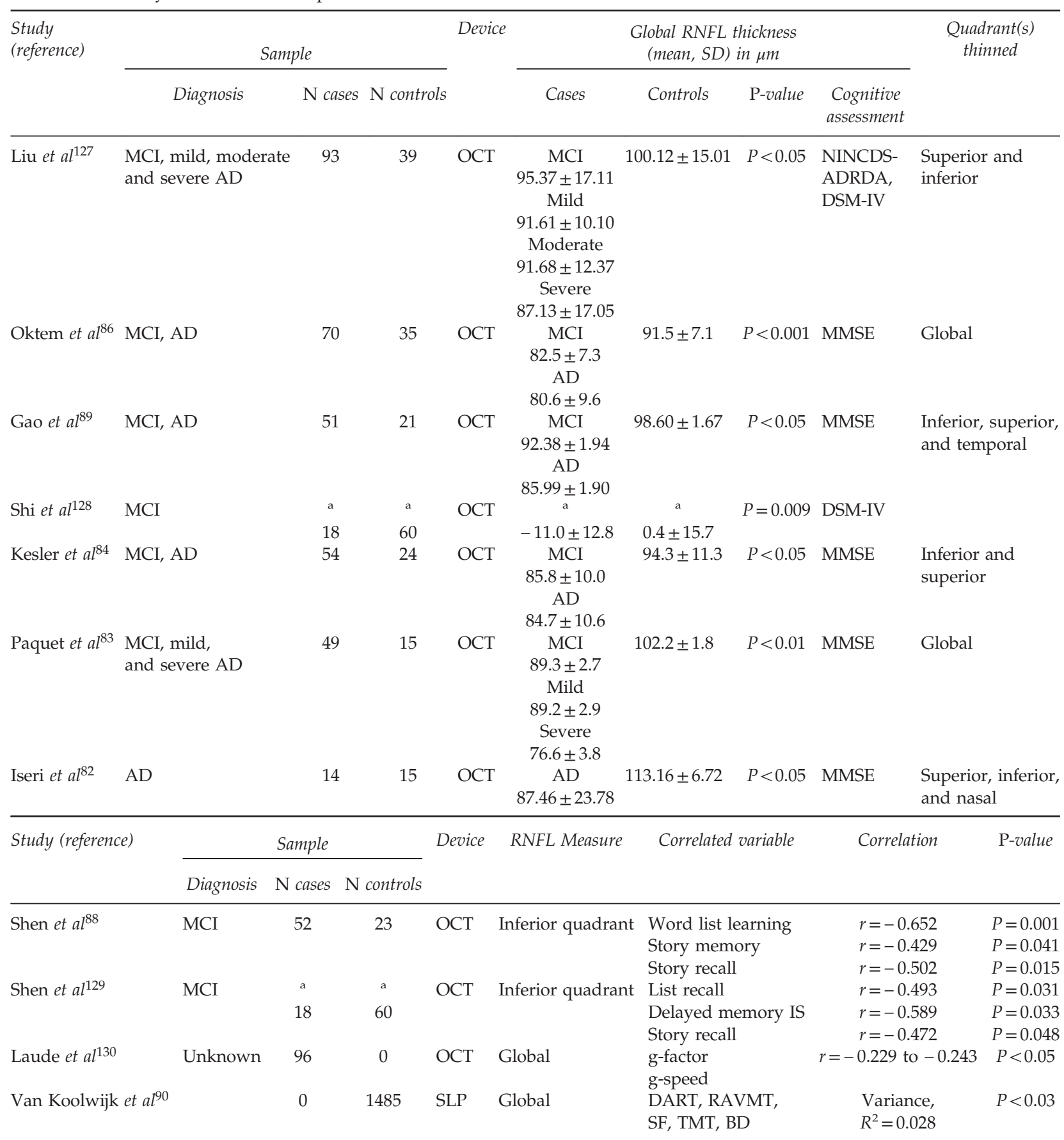

Abbreviations: BD, block design; CI, cognitive impairment; DART, Dutch adult reading test; DSM-IV, Diagnostic and Statistical Manual of Mental Disorders; g-factor, general cognitive ability; g-speed, general processing; IS, index score; MMSE, mini mental state examination; MOCA, Montreal cognitive assessment; NINCDS-ADRDA, National Institute of Neurologic and Communicative Disorders and Stroke-Alzheimer's Disease and Related Disorders Association; RAVMT, Rey auditory verbal memory test; SF, semantic fluency; SLP, scanning laser polarimetry; TMT, trail making test. ${ }^{\text {a Subjects }}$ with normal cognition or MCI at baseline, 'cases' = progression from normal cognition to MCI, or from MCI to dementia, 'controls' = cognitively stable, values represent longitudinal change.

a $25 \%$ total reduction in the GCL in the foveal and parafoveal retina, with the greatest reduction of $52 \%$ being observed in the temporal region of the fovea. ${ }^{93}$ Neuronal loss appeared most prominent in the superior and inferior quadrants. ${ }^{94}$ These findings are consistent with the clinical case-control series reported above of greater loss in the superior and inferior quadrants in AD patients compared with controls. Not all studies, 
however, have found significant RGC loss or optic neuropathy in AD. ${ }^{95,96} \mathrm{~A}$ study using the RTVue-100 (Optovue, Inc., Fremont, CA, USA) for global RNFL+GCL thickness measurements showed significant differences between $\mathrm{AD}$ and controls. ${ }^{97}$ Studies using OCT have demonstrated a significant reduction in ganglion cellinner plexiform layer in $\mathrm{AD}$ and $\mathrm{MCI}$ patients ${ }^{98}$ and have further established its association with decreasing grey matter volume in the occipital and temporal lobes. ${ }^{99}$

\section{Animal disease models of $A D$ and the GCL}

Liu et al ${ }^{69}$ used the single transgenic mouse model Tg2576 containing an APP mutant gene, which results in agedependent cognitive deficits along with deposits of extracellular $\mathrm{AB}$ and amyloid plaques in the cortex, cerebellum, and hippocampus. ${ }^{100} \mathrm{AB}$ deposits were mainly found in the GCL and outer nuclear layer, but also in some cases the photoreceptor layer and the ONH. Double transgenic mouse models have supported these findings, with RGCs undergoing apoptosis and APP deposition occurring in the GCL and inner nuclear layer. ${ }^{101}$ Other studies of human tau transgenic mice ${ }^{79}$ have reported accumulations of hyperphosphorylated transgenic tau in the RNFL and RGCs. Other transgenic mice models have suggested that the inner plexiform layer may be a more sensitive biomarker for detecting AD-related changes compared with RGCs, ${ }^{70,80}$ making it difficult to draw firm conclusions. ${ }^{102}$

However, both human and mouse studies suggest that AD-related pathology is seen in the retina. RGC loss may be a useful biomarker for assessing the neurodegenerative processes in AD, whether it reflects local pathology or reflects global loss of cortical neurons. Further investigation into the use of RNFL measurement to reflect $\mathrm{AD}$ is required, particularly as studies to date have been cross-sectional and its use as a tool for monitoring disease progression requires further larger, longitudinal studies.

\section{The RNFL in MS}

\section{MS with ON}

MS is an autoimmune disorder affecting the central nervous system (CNS). The characteristic pathophysiological features of inflammation and demyelination lead to axonal and neuronal degeneration that can affect the anterior visual pathway, ${ }^{103}$ with $20-50 \%$ of MS cases initially presenting with optic neuritis (ON). ${ }^{104}$ Parisi et al ${ }^{105}$ first investigated patients with MS who had a previous history of ON using OCT. Results showed a $46 \%$ reduction in RNFL thickness in eyes affected by $\mathrm{ON}$ in comparison with control subjects and a $28 \%$ reduction in RNFL in affected eyes when compared with unaffected eyes of the same patient. Macular volume is also lost in eyes affected with ON when compared with disease-free control eyes. ${ }^{14}$

Significant RNFL thinning was found after $\mathrm{ON}$ in a study by Henderson et al, ${ }^{106}$ evident within 3 months with $99 \%$ of the total loss occurring within 5 months of the episode of ON. Eyes with greater RNFL loss had a worse visual prognosis at 3 months. Recurrent attacks of ON significantly reduce RNFL thickness compared with eyes affected by only one episode of ON (64.2 vs $86.3 \mu \mathrm{m}$, $P<0.0001) .{ }^{107}$

Further studies have compared an annual loss of $0.017 \%$ of the total RNFL thickness $(105 \mu \mathrm{m})$ in healthy control eyes ${ }^{108}$ to RNFL losses between 10 and $40 \mu \mathrm{m}$ in eyes affected with $\mathrm{ON}$, which have been reported in approximately $75 \%$ of patients with MS within a 3- to 6-month period following the acute attack of ON. ${ }^{107,108}$ These researchers ${ }^{107}$ also noted a cutoff point of $75 \mu \mathrm{m}$ for RNFL thickness, below which a notable decline in visual field sensitivity corresponded to RNFL loss. A recent review of OCT data for patients with MS showed significant differences in RNFL thickness when compared with normal controls $(95.5 \pm 14.5 \mu \mathrm{m} \text { vs } 104.5 \pm 10.7 \mu \mathrm{m})^{108}$ with more substantial degrees of thinning in MS patients with a history of ON $(85.7 \pm 19.0 \mu \mathrm{m})$.

\section{MS without ON}

Parisi's 1999 study ${ }^{105}$ demonstrated that RNFL thinning still occurs in patients with MS without any previous history of ocular involvement. The aetiology of axonal atrophy and progressive RGC loss in MS (in the absence of $\mathrm{ON}$ ) is unknown, but is presumed to be due to retrograde trans-synaptic degeneration. The RNFL is therefore a useful tool for studying axonal damage because of its unique unmyelinated structure. Gundogan et al ${ }^{109}$ investigated 39 MS patients with no previous visual symptoms. Results revealed a significant reduction in RNFL thickness $(P=0.011)$ only in the temporal quadrant. Other studies have found RNFL thinning in all quadrants, ${ }^{110}$ temporal, and inferior quadrants ${ }^{111}$ and in the superior and inferior quadrants, ${ }^{112}$ which correlated to their corresponding visual field regions. ${ }^{14}$ Gundogan et $a l^{109}$ also assessed the retinal functional status of these patients using pattern VEP, which showed significant delays in P100 latency in 60 and 15-min arc checks $(P<0.001)$ in patients with MS, however, P100 amplitude was only significantly reduced in 60-min arc checks. These findings are further supported by Sriram et al ${ }^{113}$ who demonstrated a significant latency delay and amplitude reduction in multifocal VEPs of $62 \mathrm{MS}$ patients with no previous history of $\mathrm{ON}$, and an inverse correlation of GCL, total and temporal RNFL thickness with multifocal VEP latency. 


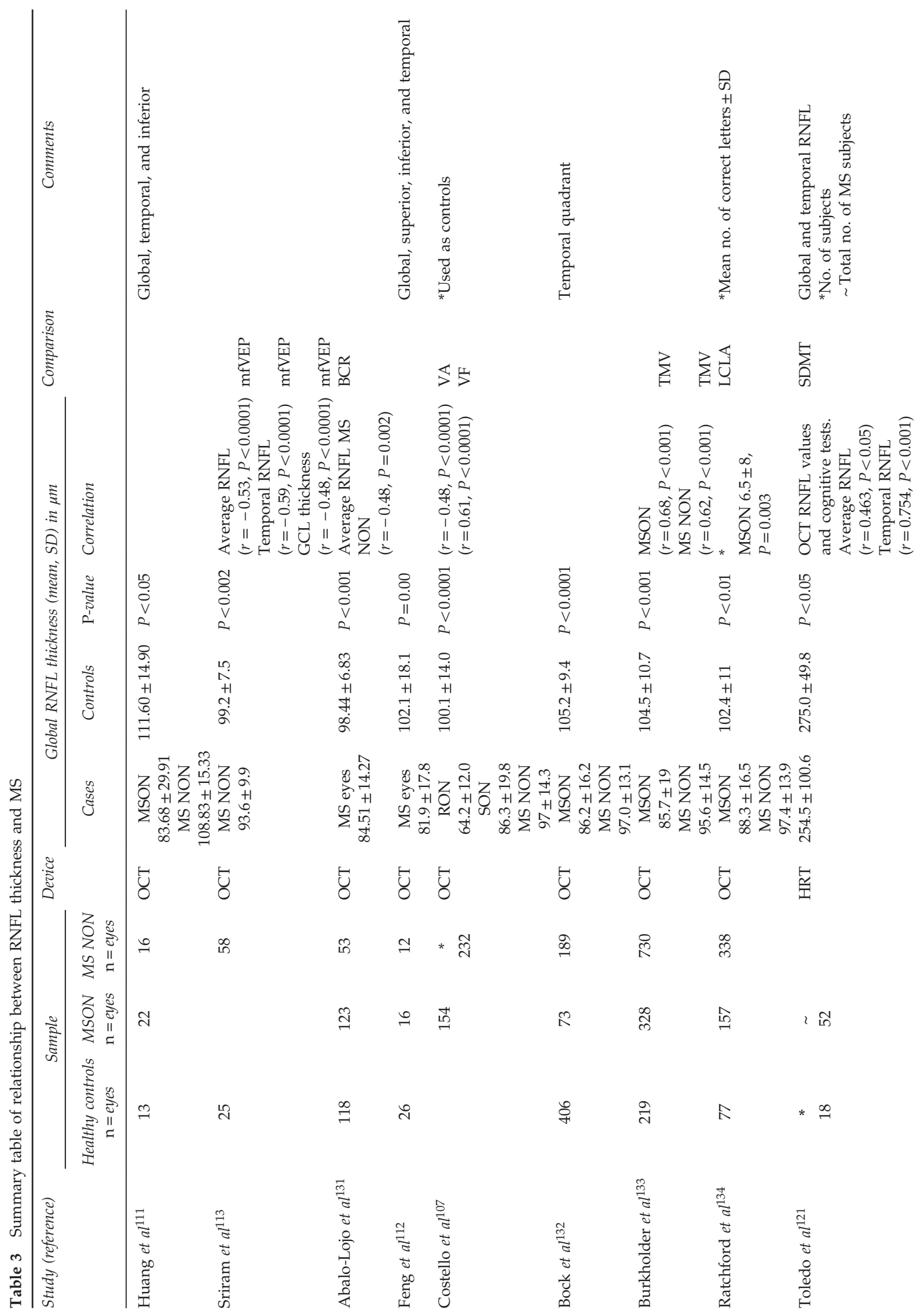




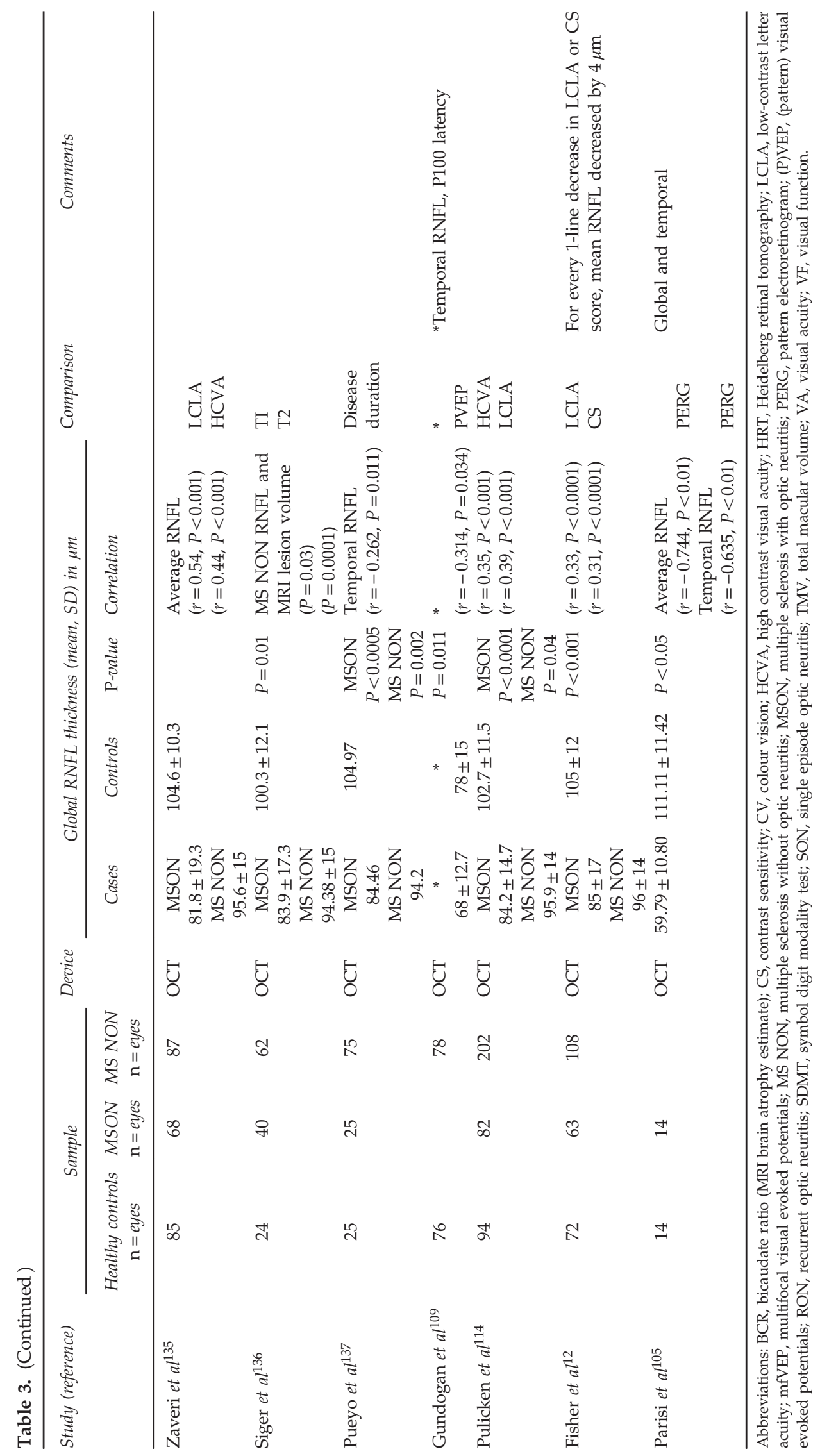


OCT measurements of RNFL thickness have also been shown to vary in the different subtypes of MS. RNFL thickness values in patients with secondary progressive MS (SPMS) were reduced in comparison with the other subtypes particularly with patients with the clinically isolated syndrome of MS (84.7 vs $105.7 \mu \mathrm{m}, P<0.0001) .{ }^{107}$ Pulicken et al ${ }^{114}$ demonstrated decreased RNFL in relapsing remitting (RRMS $94.4 \mu \mathrm{m}, P<0.001$ ), primary progressive (PPMS $88.9 \mu \mathrm{m}, P<0.01)$ and SPMS $(81.8 \mu \mathrm{m}$, $P<0.0001)$ when compared with controls. RNFL thickness and mean macular volume have also been shown to be significantly reduced in SPMS but not in PPMS. ${ }^{115}$

Macular OCT segmentation shows a significant decrease in GCL thickness ${ }^{113}$ and volume in eyes of MS patients when compared with disease-free controls. GCL and inner plexiform layer thickness measurements may predict generalised axonal damage in MS more sensitively than RNFL analysis in MS. ${ }^{116}$ Histological studies ${ }^{117}$ have corroborated OCT findings, identifying involvement of the inner nuclear layer, with significant atrophy noted in $40 \%$ of MS eyes, with no atrophy in control eyes. In addition, the degree of retinal atrophy was inversely associated with brain weight, that is, loss of RGCs appears related to loss of cortical volume, potentially reflecting the overall burden of disease. The amount of retinal atrophy also appeared to reflect a longer duration of MS. ${ }^{117}$

A meta-analysis conducted by Petzold et al ${ }^{118}$ of time domain OCT data from 32 studies showed less but significant RNFL thinning (7.08 $\mu \mathrm{m}$ (5.52-8.65, $n=3154$, $P<0.0001)$ ) in eyes of MS patients without ON. Overall, these studies (Table 3) demonstrate consistent findings that the neurodegenerative processes of neuro-axonal loss are reflected in the retina and therefore the RNFL and potentially the RGC layer are useful tools for quantification of these changes. These potential biomarkers are important, as RNFL thickness has been shown to correlate with disability in MS, ${ }^{107}$ and they are currently being used in clinical trials (ClinicalTrials.gov, ID NCT01838174, ID NCT02273635).

\section{Cognitive impairment in MS}

A variety of symptoms, including cognitive, motor, and neuro-psychiatric abnormalities develop in MS because of the pathophysiological features of widespread lesions in the brain and spinal cord. ${ }^{119}$ As well as visual symptoms, cognitive impairment is also common in MS with prevalence rates ranging between 40 and 65\% depending on study settings ${ }^{120}$ and the subtype of MS. ${ }^{119}$ Various cognitive domains are affected in MS, particularly processing speed and immediate and delayed visual memory, but also information processing efficiency, attention, executive functioning, and long-term memory. Least affected domains include the main verbal skills such as comprehension and fluency. ${ }^{119}$

Studies have shown significant correlations between RNFL atrophy and cognitive disability, in particular attention and executive deficits, assessed using the symbol digit modality test in patients with MS when compared with healthy controls. ${ }^{121}$ These findings may be explained by the reported correlations between RNFL thickness and brain atrophy. ${ }^{122,123}$ Not all studies have found the same, however, others have reported an association between cognitive impairment in MS patients and performance in visual function tests such as low contrast sensitivity testing. ${ }^{124}$

Early detection of cognitive dysfunction is important, as cognitive symptoms significantly impact the quality of life in MS patients. ${ }^{125}$ Further research is required to confirm whether RNFL or other ocular biomarkers are sensitive or specific in early detection of cognitive impairment in MS, to allow more aggressive management to reduce progression, or if the cognitive dysfunction merely reflects overall disease burden, which in turn is reflected in RNFL measures.

\section{Summary}

This review has highlighted the associations between neurodegenerative processes such as glaucoma and AD and ocular structures such as the RNFL and GCL. Evidence from animal and human studies is accumulating of a link between CNS degeneration (seen in AD and MS) and RNFL thinning; reflecting both retrograde transynaptic loss of RGCs and the same primary pathological process affecting the retina as in the brain (in $\mathrm{AD}$ ). Given that patients with early disease (MCI) have thinning of the RNFL, as well as in later AD, and more severe MS phenotypes have thinner RNFL than those with less severe MS, loss of RNFL may be a useful biomarker of neurodegeneration, and in particular superior RNFL loss seems to reflect early disease in AD.

A limitation of most of the studies investigating ocular changes is their small sample sizes, and they are to date mostly cross-sectional. There is limited longitudinal data to date, and no assessment of sensitivity and specificity to change. Therefore, the challenge remains to find a specific ocular biomarker with sufficient sensitivity to detect preclinical disease and to monitor progression accurately. OCT carries many advantages, as it provides an inexpensive, non-invasive approach for visualising the CNS, and obtaining quantitative measurements of ocular morphologies that have been implicated in neurodegenerative processes. However, these ocular changes are not disease specific, and are complicated by the fact that both glaucoma and $\mathrm{AD}$ are strongly age 
related, and that therefore the signs overlap and attribution of RNFL thinning to one pathology rather than the other may be difficult. The effect size is generally small: with an average loss of $11 \mu \mathrm{m}$, range of $6.2-25.7 \mu \mathrm{m}$ in $\mathrm{AD}$ patients when compared with controls, and $7 \mu \mathrm{m}$ in MS patients without ON compared with a normal RNFL thickness of $\sim 100 \mu \mathrm{m}$.

We find encouraging data to support the retina as a potential ocular biomarker for evaluation of disease progression in $\mathrm{AD}$ and other neurodegenerative processes with similar pathophysiological mechanisms. However, further longitudinal studies with larger sample sizes are needed to judge sensitivity and specificity to disease progression. Clinical trials are in progress using OCT to determine whether ocular parameters including RNFL thickness may prove to be useful indicators for detection of early $\mathrm{AD}$ and decline in cognitive function.

\section{Conflict of interest}

The authors declare no conflict of interest.

\section{References}

1 Bowd C, Weinreb RN, Williams JM, Zangwill LM. The retinal nerve fiber layer thickness in ocular hypertensive, normal, and glaucomatous eyes with optical coherence tomography. Arch Ophthalmol 2000; 118(1): 22-26.

2 Quigley HA, Addicks EM, Green WR. Optic nerve damage in human glaucoma. III. Quantitative correlation of nerve fiber loss and visual field defect in glaucoma, ischemic neuropathy, papilledema, and toxic neuropathy. Arch Ophthalmol 1982; 100(1): 135-146.

3 Quigley HA, Miller NR, George T. Clinical evaluation of nerve fiber layer atrophy as an indicator of glaucomatous optic nerve damage. Arch Ophthalmol 1980; 98(9): 1564-1571.

4 Sommer A, Miller NR, Pollack I, Maumenee AE, George T. The nerve fiber layer in the diagnosis of glaucoma. Arch Ophthalmol 1977; 95(12): 2149-2156.

5 Michelson G, Warntges S, Hornegger J, Lausen B. The papilla as screening parameter for early diagnosis of glaucoma. Dtsch Arztebl Int 2008; 105(34-35): 583-589.

6 Sommer A, Katz J, Quigley HA, Miller NR, Robin AL, Richter RC et al. Clinically detectable nerve fiber atrophy precedes the onset of glaucomatous field loss. Arch Ophthalmol 1991; 109(1): 77-83.

7 Bussel, Wollstein G, Schuman JS. OCT for glaucoma diagnosis, screening and detection of glaucoma progression. Br J Ophthalmol 2014; 98(Suppl 2): ii15-ii19.

8 Wessel JM, Horn FK, Tornow RP, Schmid M, Mardin CY, Kruse FE et al. Longitudinal analysis of progression in glaucoma using spectral-domain optical coherence tomography. Invest Ophthalmol Vis Sci 2013; 54(5): 3613-3620.

9 Kromer R, Serbecic N, Hausner L, Froelich L, Aboul-Enein F, Beutelspacher SC. Detection of retinal nerve fiber layer defects in Alzheimer's disease using SD-OCT. Front Psychiatry 2014; 5: 22.
10 Lu Y, Li Z, Zhang X, Ming B, Jia J, Wang R et al. Retinal nerve fiber layer structure abnormalities in early Alzheimer's disease: evidence in optical coherence tomography. Neurosci Lett 2010; 480(1): 69-72.

11 Parisi V, Restuccia R, Fattapposta F, Mina C, Bucci MG, Pierelli F. Morphological and functional retinal impairment in Alzheimer's disease patients. Clin Neurophysiol 2001; 112(10): 1860-1867.

12 Fisher JB, Jacobs DA, Markowitz CE, Galetta SL, Volpe NJ, Nano-Schiavi ML et al. Relation of visual function to retinal nerve fiber layer thickness in multiple sclerosis. Ophthalmology 2006; 113(2): 324-332.

13 Sepulcre J, Murie-Fernandez M, Salinas-Alaman A, Garcia-Layana A, Bejarano B, Villoslada P. Diagnostic accuracy of retinal abnormalities in predicting disease activity in MS. Neurology 2007; 68(18): 1488-1494.

14 Trip SA, Schlottmann PG, Jones SJ, Altmann DR, Garway-Heath DF, Thompson AJ et al. Retinal nerve fiber layer axonal loss and visual dysfunction in optic neuritis. Ann Neurol 2005; 58(3): 383-391.

15 Duckett $\mathrm{S}$. The establishment of internal vascularization in the human telencephalon. Acta Anat 1971; 80(1): 107-113.

16 Hughes S, Yang H, Chan-Ling T. Vascularization of the human fetal retina: roles of vasculogenesis and angiogenesis. Invest Ophthalmol Vis Sci 2000; 41(5): 1217-1228.

17 Kwa VI, van der Sande JJ, Stam J, Tijmes N, Vrooland JL. Amsterdam Vascular Medicine G. Retinal arterial changes correlate with cerebral small-vessel disease. Neurology 2002; 59(10): 1536-1540.

18 Wong TY, Klein R, Nieto FJ, Moraes SA, Mosley TH, Couper DJ et al. Is early age-related maculopathy related to cognitive function? The Atherosclerosis Risk in Communities Study. Am J Ophthalmol 2002; 134(6): 828-835.

19 Wong TY, Klein R, Sharrett AR, Nieto FJ, Boland LL, Couper DJ et al. Retinal microvascular abnormalities and cognitive impairment in middle-aged persons: the Atherosclerosis Risk in Communities Study. Stroke 2002; 33(6): 1487-1492.

20 Huang D, Swanson EA, Lin CP, Schuman JS, Stinson WG, Chang W et al. Optical coherence tomography. Science 1991; 254(5035): 1178-1181.

21 Sommer A, Quigley HA, Robin AL, Miller NR, Katz J, Arkell S. Evaluation of nerve fiber layer assessment. Arch Ophthalmol 1984; 102(12): 1766-1771.

22 Quigley HA, Sommer A. How to use nerve fiber layer examination in the management of glaucoma. Trans Am Ophthalmol Soc 1987; 85: 254-272.

23 Weinreb RN, Shakiba S, Zangwill L. Scanning laser polarimetry to measure the nerve fiber layer of normal and glaucomatous eyes. Am J Ophthalmol 1995; 119(5): 627-636.

24 Bowd C, Tavares IM, Medeiros FA, Zangwill LM, Sample PA, Weinreb RN. Retinal nerve fiber layer thickness and visual sensitivity using scanning laser polarimetry with variable and enhanced corneal compensation. Ophthalmology 2007; 114(7): 1259-1265.

25 Brusini P, Salvetat ML, Parisi L, Zeppieri M, Tosoni C. Discrimination between normal and early glaucomatous eyes with scanning laser polarimeter with fixed and variable corneal compensator settings. Eur J Ophthalmol 2005; 15(4): 468-476.

26 Da Pozzo S, Iacono P, Marchesan R, Fantin A, Ravalico G. Scanning laser polarimetry with variable corneal compensation and detection of glaucomatous optic 
neuropathy. Graefe's Arch Clin Exp Ophthalmol 2005; 243(8): 774-779.

27 Mai TA, Reus NJ, Lemij HG. Retinal nerve fiber layer measurement repeatability in scanning laser polarimetry with enhanced corneal compensation. J Glaucoma 2008; 17(4): 269-274.

28 Reus NJ, Lemij HG. Diagnostic accuracy of the GDx VCC for glaucoma. Ophthalmology 2004; 111(10): 1860-1865.

29 Kruse FE, Burk RO, Volcker HE, Zinser G, Harbarth U. Reproducibility of topographic measurements of the optic nerve head with laser tomographic scanning. Ophthalmology 1989; 96(9): 1320-1324.

30 Zangwill LM, Weinreb RN, Beiser JA, Berry CC, Cioffi GA, Coleman AL et al. Baseline topographic optic disc measurements are associated with the development of primary open-angle glaucoma: the Confocal Scanning Laser Ophthalmoscopy Ancillary Study to the Ocular Hypertension Treatment Study. Arch Ophthalmol 2005; 123(9): 1188-1197.

31 Bowd C, Zangwill LM, Berry CC, Blumenthal EZ, Vasile C, Sanchez-Galeana $C$ et al. Detecting early glaucoma by assessment of retinal nerve fiber layer thickness and visual function. Invest Ophthalmol Vis Sci 2001; 42(9): 1993-2003.

32 Leung CK, Choi N, Weinreb RN, Liu S, Ye C, Liu L et al. Retinal nerve fiber layer imaging with spectral-domain optical coherence tomography: pattern of RNFL defects in glaucoma. Ophthalmology 2010; 117(12): 2337-2344.

33 Reitz C, Brayne C, Mayeux R. Epidemiology of Alzheimer disease. Nat Rev Neurol 2011; 7(3): 137-152.

34 Alzheimer's A. 2014 Alzheimer's disease facts and figures. Alzheimer's Dement 2014; 10(2): e47-e92.

35 Lambert JC, Ibrahim-Verbaas CA, Harold D, Naj AC, Sims R, Bellenguez C et al. Meta-analysis of 74046 individuals identifies 11 new susceptibility loci for Alzheimer's disease. Nat Genet 2013; 45(12): 1452-1458.

36 Reiman EM, Quiroz YT, Fleisher AS, Chen K, Velez-Pardo C, Jimenez-Del-Rio $\mathrm{M}$ et al. Brain imaging and fluid biomarker analysis in young adults at genetic risk for autosomal dominant Alzheimer's disease in the presenilin 1 E280A kindred: a case-control study. Lancet Neurol 2012; 11(12): 1048-1056.

37 Jack Jr CR, Lowe VJ, Weigand SD, Wiste HJ, Senjem ML, Knopman DS et al. Serial PIB and MRI in normal, mild cognitive impairment and Alzheimer's disease: implications for sequence of pathological events in Alzheimer's disease. Brain 2009; 132(Pt 5): 1355-1365.

38 Villemagne VL, Burnham S, Bourgeat P, Brown B, Ellis KA, Salvado $\mathrm{O}$ et al. Amyloid beta deposition, neurodegeneration, and cognitive decline in sporadic Alzheimer's disease: a prospective cohort study. Lancet Neurol 2013; 12(4): 357-367.

39 van Oijen M, Hofman A, Soares HD, Koudstaal PJ, Breteler MM. Plasma Abeta(1-40) and Abeta(1-42) and the risk of dementia: a prospective case-cohort study. Lancet Neurol 2006; 5(8): 655-660.

40 McKinnon SJ. The cell and molecular biology of glaucoma: common neurodegenerative pathways and relevance to glaucoma. Invest Ophthalmol Vis Sci 2012; 53(5): 2485-2487.

41 Tezel G. TNF-alpha signaling in glaucomatous neurodegeneration. Prog Brain Res 2008; 173: 409-421.

42 Tobinick E. Tumour necrosis factor modulation for treatment of Alzheimer's disease: rationale and current evidence. CNS Drugs 2009; 23(9): 713-725.
43 Fonseca MI, Chu SH, Berci AM, Benoit ME, Peters DG, Kimura $Y$ et al. Contribution of complement activation pathways to neuropathology differs among mouse models of Alzheimer's disease. J Neuroinflammation 2011; 8(1): 4 .

44 Stasi K, Nagel D, Yang X, Wang RF, Ren L, Podos SM et al. Complement component $1 \mathrm{Q}$ (C1Q) upregulation in retina of murine, primate, and human glaucomatous eyes. Invest Ophthalmol Vis Sci 2006; 47(3): 1024-1029.

45 Engelborghs S, De Vreese K, Van de Casteele T, Vanderstichele H, Van Everbroeck B, Cras P et al. Diagnostic performance of a CSF-biomarker panel in autopsy-confirmed dementia. Neurobiol Aging 2008; 29(8): 1143-1159.

46 Yoneda S, Hara H, Hirata A, Fukushima M, Inomata Y, Tanihara H. Vitreous fluid levels of beta-amyloid((1-42)) and tau in patients with retinal diseases. Jpn J Ophthalmol 2005; 49(2): 106-108.

47 McKinnon SJ. Glaucoma: ocular Alzheimer's disease? Front Biosci 2003; 8: s1140-s1156.

48 Sadun AA, Bassi CJ. Optic nerve damage in Alzheimer's disease. Ophthalmology 1990; 97(1): 9-17.

49 McKinnon SJ, Lehman DM, Kerrigan-Baumrind LA, Merges CA, Pease ME, Kerrigan DF et al. Caspase activation and amyloid precursor protein cleavage in rat ocular hypertension. Invest Ophthalmol Vis Sci 2002; 43(4): 1077-1087.

50 Helmer C, Malet F, Rougier MB, Schweitzer C, Colin J, Delyfer $\mathrm{MN}$ et al. Is there a link between open-angle glaucoma and dementia? The Three-City-Alienor cohort. Ann Neurol 2013; 74(2): 171-179.

51 Tamura H, Kawakami H, Kanamoto T, Kato T, Yokoyama T, Sasaki $\mathrm{K}$ et al. High frequency of open-angle glaucoma in Japanese patients with Alzheimer's disease. J Neurol Sci 2006; 246(1-2): 79-83.

52 Tsai CS, Ritch R, Schwartz B, Lee SS, Miller NR, Chi T et al. Optic nerve head and nerve fiber layer in Alzheimer's disease. Arch Ophthalmol 1991; 109(2): 199-204.

53 Bayer AU, Ferrari F, Erb C. High occurrence rate of glaucoma among patients with Alzheimer's disease. Eur Neurol 2002; 47(3): 165-168.

54 Bayer AU, Ferrari F. Severe progression of glaucomatous optic neuropathy in patients with Alzheimer's disease. Eye 2002; 16(2): 209-212.

55 Bayer AU, Keller ON, Ferrari F, Maag KP. Association of glaucoma with neurodegenerative diseases with apoptotic cell death: Alzheimer's disease and Parkinson's disease. Am J Ophthalmol 2002; 133(1): 135-137.

56 Tsilis AG, Tsilidis KK, Pelidou SH, Kitsos G. Systematic review of the association between Alzheimer's disease and chronic glaucoma. Clin Ophthalmol 2014; 8: 2095-2104.

$57 \mathrm{Ou} \mathrm{Y,} \mathrm{Grossman} \mathrm{DS,} \mathrm{Lee} \mathrm{PP,} \mathrm{Sloan} \mathrm{FA.} \mathrm{Glaucoma,}$ Alzheimer disease and other dementia: a longitudinal analysis. Ophthalmic Epidemiol 2012; 19(5): 285-292.

58 Kessing LV, Lopez AG, Andersen PK, Kessing SV. No increased risk of developing Alzheimer disease in patients with glaucoma. J Glaucoma 2007; 16(1): 47-51.

59 Chandra V, Bharucha NE, Schoenberg BS. Conditions associated with Alzheimer's disease at death: case-control study. Neurology 1986; 36(2): 209-211.

60 Cumurcu T, Dorak F, Cumurcu BE, Erbay LG, Ozsoy E. Is there any relation between pseudoexfoliation syndrome and Alzheimer's type dementia? Semin Ophthalmol 2013; 28(4): 224-229. 
61 McKee AC, Au R, Cabral HJ, Kowall NW, Seshadri S, Kubilus CA et al. Visual association pathology in preclinical Alzheimer disease. J Neuropathol Exp Neurol 2006; 65(6): 621-630.

62 Bentley P, Driver J, Dolan RJ. Cholinesterase inhibition modulates visual and attentional brain responses in Alzheimer's disease and health. Brain 2008; 131(Pt 2): 409-424.

63 Herholz K, Weisenbach S, Zundorf G, Lenz O, Schroder H, Bauer $\mathrm{B}$ et al. In vivo study of acetylcholine esterase in basal forebrain, amygdala, and cortex in mild to moderate Alzheimer disease. NeuroImage 2004; 21(1): 136-143.

64 Cronin-Golomb A, Corkin S, Rizzo JF, Cohen J, Growdon JH, Banks KS. Visual dysfunction in Alzheimer's disease: relation to normal aging. Ann Neurol 1991; 29(1): 41-52.

65 Rizzo 3rd JF , Cronin-Golomb A, Growdon JH, Corkin S, Rosen TJ, Sandberg MA et al. Retinocalcarine function in Alzheimer's disease. A clinical and electrophysiological study. Arch Neurol 1992; 49(1): 93-101.

66 Hinton DR, Sadun AA, Blanks JC, Miller CA. Optic-nerve degeneration in Alzheimer's disease. N Engl J Med 1986; 315 (8): 485-487.

67 Koronyo-Hamaoui M, Koronyo Y, Ljubimov AV, Miller CA, Ko MK, Black KL et al. Identification of amyloid plaques in retinas from Alzheimer's patients and noninvasive in vivo optical imaging of retinal plaques in a mouse model. Neurolmage 2011; 54(Suppl 1): S204-S217.

68 Loffler KU, Edward DP, Tso MO. Immunoreactivity against tau, amyloid precursor protein, and beta-amyloid in the human retina. Invest Ophthalmol Vis Sci 1995; 36(1): 24-31.

69 Liu B, Rasool S, Yang Z, Glabe CG, Schreiber SS, Ge J et al. Amyloid-peptide vaccinations reduce $\{$ beta\}-amyloid plaques but exacerbate vascular deposition and inflammation in the retina of Alzheimer's transgenic mice. Am J Pathol 2009; 175(5): 2099-2110.

70 Perez SE, Lumayag S, Kovacs B, Mufson EJ, Xu S. Beta-amyloid deposition and functional impairment in the retina of the APPswe/PS1DeltaE9 transgenic mouse model of Alzheimer's disease. Invest Ophthalmol Vis Sci 2009; 50(2): 793-800.

71 Grunberger J, Linzmayer L, Walter H, Rainer M, Masching A, Pezawas L et al. Receptor test (pupillary dilatation after application of $0.01 \%$ tropicamide solution) and determination of central nervous activation (Fourier analysis of pupillary oscillations) in patients with Alzheimer's disease. Neuropsychobiology 1999; 40(1): 40-46.

72 Iijima A, Haida M, Ishikawa N, Ueno A, Minamitani H, Shinohara Y. Re-evaluation of tropicamide in the pupillary response test for Alzheimer's disease. Neurobiol Aging 2003; 24(6): 789-796.

73 Scinto LF, Daffner KR, Dressler D, Ransil BI, Rentz D, Weintraub $S$ et al. A potential noninvasive neurobiological test for Alzheimer's disease. Science 1994; 266(5187): 1051-1054.

74 Idiaquez J, Alvarez G, Villagra R, San Martin RA. Cholinergic supersensitivity of the iris in Alzheimer's disease. J Neurol Neurosurg Psychiatry 1994; 57(12): 1544-1545.

75 Fotiou DF, Brozou CG, Haidich AB, Tsiptsios D, Nakou M, Kabitsi A et al. Pupil reaction to light in Alzheimer's disease: evaluation of pupil size changes and mobility. Aging Clin Exp Res 2007; 19(5): 364-371.

76 Fotiou F, Fountoulakis KN, Tsolaki M, Goulas A, Palikaras A. Changes in pupil reaction to light in Alzheimer's disease patients: a preliminary report. Int J Psychophysiol 2000; 37(1): 111-120.

77 Goldstein LE, Muffat JA, Cherny RA, Moir RD, Ericsson MH, Huang $\mathrm{X}$ et al. Cytosolic beta-amyloid deposition and supranuclear cataracts in lenses from people with Alzheimer's disease. Lancet 2003; 361(9365): 1258-1265.

78 Berisha F, Feke GT, Trempe CL, McMeel JW, Schepens CL. Retinal abnormalities in early Alzheimer's disease. Invest Ophthalmol Vis Sci 2007; 48(5): 2285-2289.

79 Canobbio I, Abubaker AA, Visconte C, Torti M, Pula G. Role of amyloid peptides in vascular dysfunction and platelet dysregulation in Alzheimer's disease. Front Cell Neurosci 2015; 9: 65.

80 Williams PA, Thirgood RA, Oliphant H, Frizzati A, Littlewood E, Votruba $\mathrm{M}$ et al. Retinal ganglion cell dendritic degeneration in a mouse model of Alzheimer's disease. Neurobiol Aging 2013; 34(7): 1799-1806.

81 Hedges 3rd TR, Perez Galves R, Speigelman D, Barbas NR, Peli E, Yardley CJ. Retinal nerve fiber layer abnormalities in Alzheimer's disease. Acta Ophthalmol Scand 1996; 74(3): 271-275.

82 Iseri PK, Altinas O, Tokay T, Yuksel N. Relationship between cognitive impairment and retinal morphological and visual functional abnormalities in Alzheimer disease. J Neuroophthalmol 2006; 26(1): 18-24.

83 Paquet C, Boissonnot M, Roger F, Dighiero P, Gil R, Hugon J. Abnormal retinal thickness in patients with mild cognitive impairment and Alzheimer's disease. Neurosci Lett 2007; 420(2): 97-99.

84 Kesler A, Vakhapova V, Korczyn AD, Naftaliev E, Neudorfer M. Retinal thickness in patients with mild cognitive impairment and Alzheimer's disease. Clin Neurol Neurosurg 2011; 113(7): 523-526.

85 Trick GL, Trick LR, Morris P, Wolf M. Visual field loss in senile dementia of the Alzheimer's type. Neurology 1995; 45(1): 68-74.

86 Oktem EO, Derle E, Kibaroglu S, Oktem C, Akkoyun I, Can $\mathrm{U}$. The relationship between the degree of cognitive impairment and retinal nerve fiber layer thickness. Neurol Sci 2015; 36(7): 1141-1146.

87 Tatham AJ, Boer ER, Rosen PN, Della Penna M, Meira-Freitas D, Weinreb RN et al. Glaucomatous retinal nerve fiber layer thickness loss is associated with slower reaction times under a divided attention task. Am J Ophthalmol 2014; 158(5): 1008-1017.

88 Shen Y, Liu L, Cheng Y, Feng W, Shi Z, Zhu Y et al. Retinal nerve fiber layer thickness is associated with episodic memory deficit in mild cognitive impairment patients. Curr Alzheimer Res 2014; 11(3): 259-266.

89 Gao L, Liu Y, Li X, Bai Q, Liu P. Abnormal retinal nerve fiber layer thickness and macula lutea in patients with mild cognitive impairment and Alzheimer's disease. Arch Gerontol Geriatr 2015; 60(1): 162-167.

90 van Koolwijk LM, Despriet DD, Van Duijn CM, Oostra BA, van Swieten JC, de Koning I et al. Association of cognitive functioning with retinal nerve fiber layer thickness. Invest Ophthalmol Vis Sci 2009; 50(10): 4576-4580.

91 Tan O, Chopra V, Lu AT, Schuman JS, Ishikawa H, Wollstein G et al. Detection of macular ganglion cell loss in glaucoma by Fourier-domain optical coherence tomography. Ophthalmology 2009; 116(12): 2305-2314 e2301-2302. 
92 Blanks JC, Hinton DR, Sadun AA, Miller CA. Retinal ganglion cell degeneration in Alzheimer's disease. Brain Res 1989; 501(2): 364-372.

93 Blanks JC, Torigoe Y, Hinton DR, Blanks RH. Retinal pathology in Alzheimer's disease. I. Ganglion cell loss in foveal/parafoveal retina. Neurobiol Aging 1996; 17(3): 377-384.

94 Blanks JC, Schmidt SY, Torigoe Y, Porrello KV, Hinton DR, Blanks RH. Retinal pathology in Alzheimer's disease. II. Regional neuron loss and glial changes in GCL. Neurobiol Aging 1996; 17(3): 385-395.

95 Curcio CA, Drucker DN. Retinal ganglion cells in Alzheimer's disease and aging. Ann Neurol 1993; 33(3): 248-257.

96 Davies DC, McCoubrie P, McDonald B, Jobst KA. Myelinated axon number in the optic nerve is unaffected by Alzheimer's disease. Br J Ophthalmol 1995; 79(6): 596-600.

97 Marziani E, Pomati S, Ramolfo P, Cigada M, Giani A, Mariani $C$ et al. Evaluation of retinal nerve fiber layer and ganglion cell layer thickness in Alzheimer's disease using spectral-domain optical coherence tomography. Invest Ophthalmol Vis Sci 2013; 54(9): 5953-5958.

98 Cheung CY, Ong YT, Hilal S, Ikram MK, Low S, Ong YL et al. Retinal ganglion cell analysis using high-definition optical coherence tomography in patients with mild cognitive impairment and Alzheimer's disease. J Alzheimers Dis 2015; 45(1): 45-56.

99 Ong YT, Hilal S, Cheung CY, Venketasubramanian N, Niessen WJ, Vrooman H et al. Retinal neurodegeneration on optical coherence tomography and cerebral atrophy. Neurosci Lett 2015; 584: 12-16.

100 Hsiao K, Chapman P, Nilsen S, Eckman C, Harigaya Y, Younkin $\mathrm{S}$ et al. Correlative memory deficits, Abeta elevation, and amyloid plaques in transgenic mice. Science 1996; 274(5284): 99-102.

101 Ning A, Cui J, To E, Ashe KH, Matsubara J. Amyloid-beta deposits lead to retinal degeneration in a mouse model of Alzheimer disease. Invest Ophthalmol Vis Sci 2008; 49(11): 5136-5143.

102 Parnell M, Guo L, Abdi M, Cordeiro MF. Ocular manifestations of Alzheimer's disease in animal models. Int I Alzheimers Dis 2012; 2012: 786494.

103 Trapp BD, Peterson J, Ransohoff RM, Rudick R, Mork S, Bo L. Axonal transection in the lesions of multiple sclerosis. N Engl J Med 1998; 338(5): 278-285.

104 Rebolleda G, Diez-Alvarez L, Casado A, Sanchez-Sanchez C, de Dompablo E, Gonzalez-Lopez JJ et al. OCT: new perspectives in neuro-ophthalmology. Saudi J Ophthalmol 2015; 29(1): 9-25.

105 Parisi V, Manni G, Spadaro M, Colacino G, Restuccia R, Marchi $S$ et al. Correlation between morphological and functional retinal impairment in multiple sclerosis patients. Invest Ophthalmol Vis Sci 1999; 40(11): 2520-2527.

106 Henderson AP, Altmann DR, Trip AS, Kallis C, Jones SJ, Schlottmann PG et al. A serial study of retinal changes following optic neuritis with sample size estimates for acute neuroprotection trials. Brain 2010; 133(9): 2592-2602.

107 Costello F, Hodge W, Pan YI, Eggenberger E, Freedman MS. Using retinal architecture to help characterize multiple sclerosis patients. Can J Ophthalmol 2010; 45(5): 520-526.

108 Balcer LJ. Clinical trials to clinical use: using vision as a model for multiple sclerosis and beyond. J Neuroophthalmol 2014; 34(Suppl): S18-S23.
109 Gundogan FC, Demirkaya S, Sobaci G. Is optical coherence tomography really a new biomarker candidate in multiple sclerosis?-A structural and functional evaluation. Invest Ophthalmol Vis Sci 2007; 48(12): 5773-5781.

110 Costello F, Coupland S, Hodge W, Lorello GR, Koroluk J, Pan YI et al. Quantifying axonal loss after optic neuritis with optical coherence tomography. Ann Neurol 2006; 59(6): 963-969.

111 Huang J, Dai H, Zhang H, Wang X, Chen T. [Clinical investigation of optic coherence tomography in evaluating the impairment of optic nerve secondary to multiple sclerosis]. Zhonghua Yan Ke Za Zhi 2014; 50(12): 900-905.

112 Feng L, Shen J, Jin X, Li J, Li Y. The evaluation of the retinal nerve fiber layer in multiple sclerosis with special-domain optical coherence tomography. Ophthalmologica 2013; 230(3): 116-120.

113 Sriram P, Wang C, Yiannikas C, Garrick R, Barnett M, Parratt $\mathrm{J}$ et al. Relationship between optical coherence tomography and electrophysiology of the visual pathway in non-optic neuritis eyes of multiple sclerosis patients. PLoS One 2014; 9(8): e102546.

114 Pulicken M, Gordon-Lipkin E, Balcer LJ, Frohman E, Cutter G, Calabresi PA. Optical coherence tomography and disease subtype in multiple sclerosis. Neurology 2007; 69(22): 2085-2092.

115 Henderson AP, Trip SA, Schlottmann PG, Altmann DR, Garway-Heath DF, Plant GT et al. An investigation of the retinal nerve fibre layer in progressive multiple sclerosis using optical coherence tomography. Brain 2008; 131(Pt 1): 277-287.

116 Garcia-Martin E, Polo V, Larrosa JM, Marques ML, Herrero R, Martin J et al. Retinal layer segmentation in patients with multiple sclerosis using spectral domain optical coherence tomography. Ophthalmology 2014; 121(2): 573-579.

117 Green AJ, McQuaid S, Hauser SL, Allen, Lyness R. Ocular pathology in multiple sclerosis: retinal atrophy and inflammation irrespective of disease duration. Brain 2010; 133(Pt 6): 1591-1601.

118 Petzold A, de Boer JF, Schippling S, Vermersch P, Kardon $\mathrm{R}$, Green A et al. Optical coherence tomography in multiple sclerosis: a systematic review and meta-analysis. Lancet Neurol 2010; 9(9): 921-932.

119 Chiaravalloti ND, DeLuca J. Cognitive impairment in multiple sclerosis. Lancet Neurol 2008; 7(12): 1139-1151.

120 Julian LJ. Cognitive functioning in multiple sclerosis. Neurol Clin 2011; 29(2): 507-525.

121 Toledo J, Sepulcre J, Salinas-Alaman A, Garcia-Layana A Murie-Fernandez M, Bejarano B et al. Retinal nerve fiber layer atrophy is associated with physical and cognitive disability in multiple sclerosis. Mult Scler 2008; 14(7): 906-912.

122 Dorr J, Wernecke KD, Bock M, Gaede G, Wuerfel JT, Pfueller CF et al. Association of retinal and macular damage with brain atrophy in multiple sclerosis. PloS One 2011; 6(4): e18132.

123 Grazioli E, Zivadinov R, Weinstock-Guttman B, Lincoff N, Baier M, Wong JR et al. Retinal nerve fiber layer thickness is associated with brain MRI outcomes in multiple sclerosis. J Neurol Sci 2008; 268(1-2): 12-17.

124 Wieder L, Gade G, Pech LM, Zimmermann H, Wernecke KD, Dorr JM et al. Low contrast visual acuity testing is associated with cognitive performance in multiple sclerosis: a crosssectional pilot study. BMC Neurol 2013; 13: 167. 
125 Rao SM, Leo GJ, Bernardin L, Unverzagt F. Cognitive dysfunction in multiple sclerosis. I. Frequency, patterns, and prediction. Neurology 1991; 41(5): 685-691.

126 Ekstrom C, Kilander L. Pseudoexfoliation and Alzheimer's disease: a population-based 30-year follow-up study. Acta Ophthalmol 2014; 92(4): 355-358.

127 Liu D, Zhang L, Li Z, Zhang X, Wu Y, Yang H et al. Thinner changes of the retinal nerve fiber layer in patients with mild cognitive impairment and Alzheimer's disease. BMC Neurol 2015; 15: 14.

128 Shi Z, Wu Y, Wang M, Cao J, Feng W, Cheng Y et al. Greater attenuation of retinal nerve fiber layer thickness in Alzheimer's disease patients. J Alzheimers Dis 2014; 40(2): 277-283.

129 Shen Y, Shi Z, Jia R, Zhu Y, Cheng Y, Feng W et al. The attenuation of retinal nerve fiber layer thickness and cognitive deterioration. Front Cell Neurosci 2013; 7: 142.

130 Laude A, Lascaratos G, Henderson RD, Starr JM, Deary IJ Dhillon B. Retinal nerve fiber layer thickness and cognitive ability in older people: the Lothian Birth Cohort 1936 study. BMC Ophthalmol 2013; 13: 28.

131 Abalo-Lojo JM, Limeres CC, Gomez MA, BaleatoGonzalez S, Cadarso-Suarez C, Capeans-Tome C et al. Retinal nerve fiber layer thickness, brain atrophy, and disability in multiple sclerosis patients. J Neuroophthalmol 2014; 34(1): 23-28
132 Bock M, Brandt AU, Dorr J, Kraft H, Weinges-Evers N Gaede $\mathrm{G}$ et al. Patterns of retinal nerve fiber layer loss in multiple sclerosis patients with or without optic neuritis and glaucoma patients. Clin Neurol Neurosurg 2010; 112(8): 647-652.

133 Burkholder BM, Osborne B, Loguidice MJ, Bisker E, Frohman TC, Conger A et al. Macular volume determined by optical coherence tomography as a measure of neuronal loss in multiple sclerosis. Arch Neurol 2009; 66(11): 1366-1372.

134 Ratchford JN, Quigg ME, Conger A, Frohman T, Frohman E, Balcer LJ et al. Optical coherence tomography helps differentiate neuromyelitis optica and MS optic neuropathies. Neurology 2009; 73(4): 302-308.

135 Zaveri MS, Conger A, Salter A, Frohman TC, Galetta SL, Markowitz CE et al. Retinal imaging by laser polarimetry and optical coherence tomography evidence of axonal degeneration in multiple sclerosis. Arch Neurol 2008; 65(7): 924-928.

136 Siger M, Dziegielewski K, Jasek L, Bieniek M, Nicpan A, Nawrocki J et al. Optical coherence tomography in multiple sclerosis. J Neurol 2008; 255(10): 1555-1560.

137 Pueyo V, Martin J, Fernandez J, Almarcegui C, Ara J, Egea $\mathrm{C}$ et al. Axonal loss in the retinal nerve fiber layer in patients with multiple sclerosis. Mult Scler 2008; 14(5): 609-614 